\title{
Evolution of courtship display in Estrildid finches: dance in relation to female song and plumage ornamentation
}

\author{
Masayo Soma ${ }^{1 *}$ and László Z. Garamszegi ${ }^{2 *}$ \\ ${ }^{1}$ Department of Biology, Hokkaido University, Sapporo, Japan \\ ${ }^{2}$ Department of Evolutionary Ecology, Estación Biológica de Doñana-CSIC, Seville, Spain
}

\section{Edited by:}

Michelle L. Hall, University of

Melbourne, Australia

Reviewed by:

Ivar Folstad, University of Tromsø, Norway

Nicole Geberzahn, Université Paris Ouest Nanterre La Défense, France

\section{*Correspondence.}

Masayo Soma, Department of Biology, Hokkaido University, Kita 10, Nishi 8, Kita-ku, Sapporo, 060-0810, Japan

e-mail:masayo.soma@sci.

hokudai.ac.jp;

László Z. Garamszegi, Department of Evolutionary Ecology, Estación Biológica de Doñana-CSIC,

c/Americo Vespucio, s/n 41092,

Seville, Spain

e-mail: laszlo.garamszegi@

ebd.csic.es
Estrildid finches are known for great interspecific diversity in the degree of elaboration in courtship dance, song and plumage coloration and also for the considerable sex differences in these traits within species. To study the evolution of multimodal sexual signaling in these taxa, we collected data on 85 species and analyzed them in a phylogenetic comparative study. As dances are often displayed in parallel with songs and include behavioral elements to emphasize coloration, they are likely to evolve non-independently of songs and plumage characteristics. Hence, we hypothesized that the degree of elaboration in dance would be associated with song and plumage ornamentation due to correlated responses between traits. Alternatively, each sexual signal may evolve independently of the others under the influence of different aspects of reproductive ecology or life history. Finally, because trait expression occurs in both males and females and can be caused by pleiotropic effects, we predicted correlated exaggerations of the traits between sexes as well. We found that courtship dance, song and plumage coloration evolve independently, as these traits were not correlated among species in either sex (i.e., the presence of female song was not related to female dance repertoire). However, we found evidence for correlated responses between the sexes, as species that have males with complex dances or colorful plumage also have females with exaggerated traits. Yet, selection factors acting on these traits were only partially shared between sexes. While coloration can be predicted by intraspecific brood parasitism and dance by body size in females, we were unable to reveal similar relationships in males. Our results indicate that different secondary sexual characters in Estrildid finches evolved under the influence of complicated selection factors, in which both correlated responses between sexes as well as independent selective mechanisms play roles.

Keywords: courtship display, duet, female dance, female song, monogamous songbird, phylogenetic comparative approach, sexual selection

\section{INTRODUCTION}

Theories of sexual selection are classically concerned with the evolution of secondary sexual characters that are expressed by males (Andersson, 1994). Textbook examples usually focus on song displays and plumage coloration in passerine birds (Searcy and Andersson, 1986; Hill, 1991, 2006; Searcy, 1992; Catchpole and Slater, 2008), and a large number of phylogenetic comparative studies have identified the key selection factors that shape the tremendous amount of interspecific variance in these traits (e.g., Read and Weary, 1992; Owens and Hartley, 1998; Badyaev and Hill, 2000; Dunn et al., 2001; Mountjoy and Leger, 2001; Jawor and Breitwisch, 2003; Garamszegi and Møller, 2004). Even though it is known in many animal taxa that females choose mates based on male motor performance (review in Andersson, 1994; Byers et al., 2010), non-vocal behavioral elements of the courtship display of birds, i.e., dances, have attracted relatively less attention in the comparative evolutionary context. A few distantly related taxonomic groups, including bowerbirds (e.g., Patricelli et al., 2002; Coleman et al., 2004), birds of paradise (Pruett-Jones and
Pruett-Jones, 1990; Scholes, 2008), and manakins (Prum, 1990, 1998; Bostwick and Prum, 2005; DuVal, 2007; Fusani et al., 2007) are characterized by their spectacular behavioral performance, but generally applicable explanations for how such complex traits evolve are rare (Balmford, 1991; Andersson, 1994; Madden, 2001; Galván, 2008). In addition, hardly any study considered multiple sexual traits within the same study to investigate the independent or correlated evolution of various morphological and behavioral sexual display traits.

The evolution of courtship dance in birds constitutes a case that is especially interesting for at least two reasons. First, dances are rarely performed in isolation from other sexual characters, as they are often displayed in parallel with some vocalization and include behavioral elements to emphasize coloration (e.g., Torres and Velando, 2003; Cooper and Goller, 2004; Dakin and Montgomerie, 2009; Dalziell et al., 2013). Therefore, elaborate dances are likely to evolve non-independently of songs and plumage characteristics. For example, in dabbling ducks, the repertoire size of male courtship display is larger in species with 
sexually dimorphic plumage color (Johnson, 2000) while across the sexually monochromatic species of Pelecaniformes, the complexity of male advertising display is negatively correlated with the conspicuousness of feather coloration (Galván, 2008).

Second, dances can function as interactive signals between the sexes rather than simply being a secondary sexual character of males. For example, pairs of some monogamous birds, such as the Western grebe (Nuechterlein and Storer, 1982), the blue-footed booby (Torres and Velando, 2003), and several cranes (Masatomi, 1983) jointly show intricate ceremonial behavioral sequences in a well-coordinated or synchronized way. Such mutual displays are typically observed in long-lived monogamous non-passerine birds of large body size with sexes of similar appearance as in the above examples, but are also rarely performed by songbirds. These displays can be interpreted as having similar functions to vocal duets, as they can contribute to pair formation, pair bonding, or mate guarding (Malacarne et al., 1991; Wachtmeister, 2001). Although avian vocal duets have attracted much attention (review in Hall, 2004, 2009), the evolution of non-vocal, mutual display behaviors is more veiled in mystery. Furthermore, it is a puzzling question how song and dance displays can simultaneously function and evolve as intersexual communication signals.

In general, the evolution of multimodal sexual signaling can be characterized by the combination of both independent and correlated mechanisms acting on traits and on the sexes (Figure 1). For example, sexual selection can promote the evolution of multiple sexual characters, in which multiple ornaments are favored to better convey multiple messages about male quality (Møller and Pomiankowski, 1993; Candolin, 2003), or in which an evolutionary tradeoff between different sexual signals introduces negative interspecific associations between these traits (Badyaev et al., 2002; Shutler, 2011). Accordingly, the former mechanism

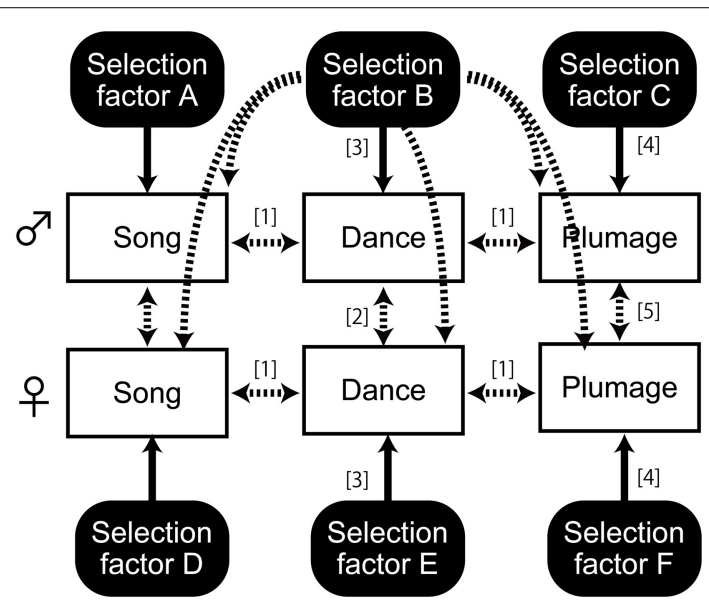

FIGURE 1 | Schematic view of the possible evolution of three sexual signals in males and females under multiple selection pressures. One-headed arrows show selection as exerted by an ecological/life history trait, and two-headed arrows show correlated responses. Solid and dashed lines show known or potential effects respectively. For illustrative purposes, the multimodal effects of particular selection pressures are only emphasized for a single factor (Selection factor B). Similar mechanisms may also apply to the other factors. would predict that the evolution of different sexual traits is under the influence of different selection regimes, which in turn would allow these traits to evolve rather independently of each other (Figure 1, arrow [4]). However, if different signals indicate the same aspect of quality or are underpinned by the same tradeoffs, different traits would be responsive to the same selection factors that would lead to the correlated evolution of these traits (Figure 1, arrow [3]). Furthermore, displays that are shared between males and females raise the question of whether these displays evolve independently or as a correlated response of the sexes. For example, mutual mate preferences promote equally exaggerated sexual signals in males and females especially in biparental species (Amundsen, 2000), while duet signaling (e.g., singing or dancing) can also contribute to pair bonding or mate guarding (Malacarne et al., 1991; Wachtmeister, 2001; Hall, 2004, 2009), both of which are expected to cause a correlated evolution of traits as a response to the same selection factors arising from reproductive ecology and/or life history. Furthermore, different traits in different sexes can be under the control of the same pleiotropic mechanisms, e.g., hormones, genes or neurotransmitters, which would couple the two traits on an evolutionary time scale (Figure 1, arrow [1]) and cause similar expressions of the same trait in both sexes (Figure 1, arrow [2]) (cf. Ketterson et al., 2005; Møller et al., 2005; but also see Garamszegi, 2014; Goymann and Wingfield, 2014).

Courtship behaviors of Estrildid finches (order: Passeriformes, family: Estrildidae) represent an ideal model for investigating the correlated evolution of audio-visual signaling. Interestingly, virtually all species are socially monogamous (Goodwin, 1982; Payne, 2010), and most of them are sedentary with only a few of them making local movements (Payne, 2010). Migration and deviations from social monogamy have been suggested to be associated with the loss of duetting and female song (Price et al., 2009; Logue and Hall, 2014) and of ornamental plumage coloration (Friedman et al., 2009). Although these driving mechanisms apparently vary little in Estrildid finches, they show great interspecific diversities in the degree of elaboration in courtship dance, presence or absence of female courtship song and dance (i.e., duet or solo performance), and also in plumage color. Furthermore, many species can be characterized by a considerable intersexual dimorphism in these sexual traits. To our knowledge, all Estrildid finches have males that show both dance and song, while females of some species do not dance or sing (Goodwin, 1982; Baptista et al., 1999; Payne, 2010). Given the monogamous breeding biology and the mutual performance of dance between sexes in some species, one can hypothesize that elaborate courtships play important roles in forming and confirming pair bonds rather than in female choice in these finches. However, the degree to which such coordinating mechanisms explain the vast heterogeneity in sexual dimorphisms in song and dance remains unknown. Understanding the evolutionary significance of dance in Estrildids is challenging, as most passerines sing without dance displays.

Our goal in this study was to investigate, by using phylogenetic comparative approaches, the evolution of mutual courtship dance in addition to their complex songs and bright plumages in Estrildids, and what selection factors shape interspecific variation 
in the complexity of dance. Specifically, to examine correlated evolutionary responses between traits, we tested if courtship dance displays in Estrildid finches show co-evolutionary exaggeration or tradeoff with other sexual displays (Figure 1). Accordingly, we predicted that interspecific variations in the presence and complexity of song displays would be associated with interspecific variations in dance displays. If songs and dances were favored for the same function, such as to advertise concordantly the same aspects of mate quality or parental investments, these selection pressures would derive positive correlations across species. Alternatively, if tradeoff mechanisms constrain the evolution of these traits, we can expect a negative interspecific association to occur. In addition, to better understand the evolutionary origins and trajectories of song and dance, we used ancestral state reconstructions and tested for phylogenetic signal. We also predicted the correlated evolution of plumage coloration and behavioral (i.e., song and dance) displays. To investigate correlated evolutionary responses between sexes, we also explored the potential effects of some characteristics of breeding ecology and life-history on the evolution of complex courtship dance acting either concordantly or separately on males and females. As a consequence of correlated evolutionary responses between sexes, we predicted a positive relationship to be detected between male and female dance repertoires, or other sexual display characters, across species. However, if independent selection mechanisms also apply, a certain proportion of the interspecific variance in dance complexity in one sex cannot be explained by interspecific variance in dance complexity in the other sex, but should be attributed to some predictor variables.

\section{MATERIALS AND METHODS}

We collected data on courtship dance, song, plumage coloration and several life-history traits of Estrildid finches from published literature. Because many Estrildids, including the well-studied zebra and Bengalese finches (Taeniopygia guttata and Lonchura striata var. domestica), are popular among aviculturists, their breeding behaviors have been documented in detail (Goodwin, 1982; Restall, 1996; Payne, 2010).

\section{COURTSHIP DANCE AND SONG}

We compiled information on dance behaviors from "Estrildid finches of the world" (Goodwin, 1982), as this source provides detailed descriptions on the behavioral sequences of social displays including courtships as well as their contextual background. The information provided by this source is reliable because it matches with other published research featuring courtship behaviors of some species (Baptista et al., 1999; Zanollo et al., 2013) and also with our direct observation of several other species (M. Soma pers. obs.). Generally in Estrildids, when a male and a female approach each other, courtship is initiated by either of the sexes, more often by males, which is sometimes followed by interactive phases in which both sexes show the same behaviors, e.g., hopping or bowing, in coordinated ways. The dance is typically terminated by females performing copulation solicitation displays that often result in copulation (Goodwin, 1982; Restall, 1996; see also Movie S1, S2). Females of some Estrildid species do not dance at all, or show only a portion of males' body movement repertoires.

Their courtship dance is stereotyped within species, and expressed as a combination of several simple actions that can be assigned into the following nine categories: (1) bobbing, i.e., up and down movement of head; (2) horizontal body movement, such as turning or changing body angle or pivoting; (3) moving wing; (4) tail movement, such as angled or spread tail; (5) erection of feathers on body; (6) hopping or stepping; (7) holding nest material in the bill; (8) bill wiping, i.e., rubbing the bill on the perch; and (9) opening the mouth or showing the tongue. Assuming that the repertoire size reflects the degree of elaboration of displays, we counted how many dance categories constitute the courtship displays of each species, separately for both males and females. We found that the repertoire of female dance is always included in the male's repertoire. When we focused on female dance repertoire size, we created statistical models in which male dance repertoire was included as a predictor variable (i.e., we avoided calculating the ratio of sex-specific repertoire owing to statistical reasons).

Unfortunately, song complexity could not be characterized in detail due to lack of published information in many species. Therefore, we scored singing behaviors for each species by first confirming male song, and then determining whether or not the female had songs (scored as 1-0), based on published descriptions in Goodwin (1982), Restall (1996) and Payne (2010).

\section{RESEARCH EFFORT}

The available information on presence of female dance and songs and repertoire of dance behaviors may be biased by the intensity of studies targeting the species (cf. Garamszegi et al., 2007). Intensively studied species may appear to have a richer dance repertoire simply because an increased research effort likely reveals rare dance elements. To control for such potential bias, we estimated research effort by counting the number of publications resulting from a keyword-based search using species' names in Web of Science, as done in other studies (Nunn et al., 2003; Lefebvre et al., 2004; Garamszegi and Møller, 2012). Estimates of research effort were log 10 transformed.

\section{PLUMAGE COLORATION}

Plumage coloration was scored by measuring the coverage of ornamental plumage coloration in each sex relying on the color plates in Payne (2010). In particular, we considered black, red, and blue/purple as these are considered major ornamental colorations in birds (e.g., Keyser and Hill, 1999; Badyaev and Hill, 2000; Jawor and Breitwisch, 2003). However, we did not apply spectrophotometric techniques, and so invisible colors such as UV could not be considered. To measure the coverage of ornamental plumage, we divided body surface into 21 plumage regions, which were belly, breast, chin, cheek, crissum, crown, flank, forehead, greater primary coverts, greater secondary coverts, lore, lesser wing coverts, mantle, median wing coverts, nape, primaries, rectrices, rump, secondaries, throat, and upper tail coverts (Andersson and Prager, 2006). We scored each region as 0: not colored, 0.5: partly colored, or 1: all colored, and summed these scores across bodies. So, for example, if a bird is all black, it is given a score 21 . In 
this way, we considered the coverage but could not differentiate color types (i.e., black, red, or blue/purple) because Estrildid finches show great among-species variation in plumage color types that are assumed to play roles in sexual contexts (Goodwin, 1982).

\section{LIFE-HISTORY TRAITS}

Information on life-history of species was compiled mainly from Payne (2010) except when otherwise stated. We considered variables that likely affect the cost of reproduction, such as incubation period in days, median clutch size, and body size taken as length. We have subsequently excluded incubation period from the set of explanatory variables to avoid multicolinearity, as our preliminary analysis revealed that it strongly correlates with body size. Estrildid finches show considerable among-species variation at least in three aspects, which can reflect differences in reproductive investment or resource competition among conspecifics. First, as some Estrildid finches in Africa are targets of interspecific brood parasitism by birds belonging to the genus Vidua (Sorenson et al., 2004), the presence or absence of interspecific brood parasitism was scored as $0-1$. Second, some Estrildid finches show intraspecific brood parasitism (Yom-Tov, 2001), which was scored as $0-1$. Third, although most species do not defend territories, the degree of gregariousness varies among species. To score this phenomenon, species were ranked as follows: colonial breeders or species with social systems in which multiple pairs keep contact with each other even during breeding season (3); highly social and gregarious but mainly outside the breeding season (2); breed usually in pairs or in small parties (1); and territorial (0).

\section{COMPARATIVE ANALYSES}

We prepared a dataset for phylogenetic comparative analyses that included 85 species, for which we could collect the above behavioral and reproductive variables from the published literature, and for which phylogenetic relationships could be abstracted from http://birdtree.org/ (Jetz et al., 2012). Our biological hypotheses were translated into statistical models that were fitted to the data and incorporated phylogenetic relatedness of species.

We first examined whether dance complexity in each sex is associated with the other sexual displays (i.e., song and plumage) and dance complexity in the other sex. Accordingly, we built a statistical model with male dance repertoire as the response variable and male plumage ornamentation as well as the presence of female song as predictor variables (Figure 1, arrow [1]) while controlling for phylogeny and research effort. In this model, we included female song to reflect the strength of selection factors acting on vocalization, because males of each species sing causing no interspecific variation in the presence of male song. In an analogous model for females, female dance repertoire was the response variable, and the predictor variables also included male dance repertoire to test for signs of correlated evolution between sexes (Figure 1, arrow [2]). Second, to investigate which life-history variables vary with exaggerated dance displays in males and females, we built statistical models for these sex-specific variables, in which we entered body size, clutch size, coloniality, presence of inter- and intraspecific parasitisms, and research effort as predictor variables (Figure 1, arrow [3]).
Again, to account for correlated responses between sexes, models on female dance also involved male dance repertoire as a predictor variable (Figure 1, arrow [2]). Additionally, we repeated the above-mentioned analyses also for plumage coloration of each sex to investigate correlated responses between behavioral and plumage ornamentation traits, while controlling for phylogeny and research effort. Specifically, we tested for a relationship between plumage coloration and the presence of female song and dance complexity in each sex (Figure 1, arrow [1]), and also analyzed if interspecific variance in life-history variables can predict interspecific variance in plumage ornamentation (Figure 1, arrow [4]). To make inferences about the correlated responses between sexes (Figure 1, arrow [5]), models on female plumage coloration considered male plumage coloration among the list of predictor variables. Due to the poor information that were available for song displays, and because males do not show any interspecific variance in the presence of song, we did not created analogs models for the vocal display traits (i.e., only used the presence of female song as response variable in the other models above).

Non-independence of data owing to the phylogenetic relatedness of species was controlled by using phylogenetic generalized least-square (PGLS) regression technique with maximumlikelihood model fitting with a variance-covariance matrix of the data based on phylogeny with the maximum-likelihood value of $\lambda$ (the strength of the phylogenetic signal). For these analyses, we could not obtain an overwhelmingly supported single phylogenetic tree with branch lengths, but we could derive multiple and equally likely candidate trees from Jetz et al. (2012). Hence, to account for such phylogenetic uncertainty, we fitted models on each of them and applied multi-model inference (Garamszegi and Mundry, 2014). Specifically, we used 1000 alternative trees from the global birdtree database for our list of species to estimate the phylogenetic parameters of interest (i.e., regression slopes) based on identical model definition in terms of the list of predictor and response variables. Then we derived mean and confidence estimates for these parameters over the pool of phylogenies via model averaging, in which parameter estimates from each model were weighted according to its relative fit to the data. We therefore present model-averaged regression slopes, SE and 95\% confidence intervals for the explanatory variables (Garamszegi and Mundry, 2014). These exercises were done using R 3.0.2 (R Core Team, 2013), relying on packages "caper" (Orme, 2012), and "AICcmodavg" (Mazerolle, 2013) and following the example codes on http://www.mpcm-evolution.org/ practice/online-practical-material-chapter-12. We opted to use multimodel inference over the pool of alternative phylogenetic trees based on information theoretic approaches instead of adopting Bayesian approaches to deal with phylogenetic uncertainty, because the latter introduces a considerable uncertainty in parameter estimates when non-informative priors are used (Garamszegi and Mundry, 2014).

Before interpreting the model outcomes, to avoid misleading results based on statistical artifacts, we performed numerous model diagnostic statistics on a PGLS model that incorporated the consensus phylogeny obtained from the birdtree sample of trees. We first checked assumptions about the distribution of 
Table 1 | Associations among three sexual signals in Estrildid finches.

\begin{tabular}{|c|c|c|c|}
\hline Explanatory variable & Coefficient & SE & $95 \% \mathrm{Cl}$ \\
\hline \multicolumn{4}{|c|}{ (A) MALE DANCE REPERTOIRE } \\
\hline Intercept & 4.484 & 0.460 & [3.582 to 5.386 ] \\
\hline Male plumage coloration & -0.001 & 0.036 & {$[-0.073$ to 0.071$]$} \\
\hline Presence of female song & -0.206 & 0.464 & [-1.115 to 0.702$]$ \\
\hline Log research effort & 0.617 & 0.249 & [0.129 to 1.105$]$ \\
\hline \multicolumn{4}{|c|}{ (B) FEMALE DANCE REPERTOIRE } \\
\hline Intercept & -1.112 & 1.007 & [-3.087 to 0.862$]$ \\
\hline Male dance repertoire & 0.537 & 0.137 & [0.270 to 0.805 ] \\
\hline Female plumage coloration & 0.004 & 0.047 & {$[-0.087$ to 0.095$]$} \\
\hline Presence of female song & 0.546 & 0.621 & [-0.670 to 1.763$]$ \\
\hline Log research effort & 0.713 & 0.301 & [0.123 to 1.303$]$ \\
\hline \multicolumn{4}{|c|}{ (C) MALE PLUMAGE COLORATION } \\
\hline Intercept & 7.609 & 1.958 & [3.771 to 11.447 ] \\
\hline Male dance repertoire & -0.057 & 0.337 & {$[-0.717$ to 0.604$]$} \\
\hline Presence of female song & 2.424 & 1.432 & {$[-0.382$ to 5.230$]$} \\
\hline Log research effort & -0.478 & 0.780 & {$[-2.007$ to 1.050$]$} \\
\hline \multicolumn{4}{|c|}{ (D) FEMALE PLUMAGE COLORATION } \\
\hline Intercept & 0.869 & 0.628 & [-0.362 to 2.100$]$ \\
\hline Male plumage coloration & 0.684 & 0.057 & [0.571 to 0.796 ] \\
\hline Female dance repertoire & -0.052 & 0.116 & [ -0.280 to 0.176$]$ \\
\hline Presence of female song & -1.128 & 0.694 & [-2.487 to 0.232$]$ \\
\hline Log research effort & -0.207 & 0.407 & {$[-1.004$ to 0.591$]$} \\
\hline
\end{tabular}

The relationship between plumage coloration and female song and dance repertoires in both males (A) and females (B) while controlling for research effort. In a similar way, we also tested if dance complexity and the presence of female song is associated with plumage coloration in the two sexes Imales (C) and females (D)]. Each coefficient was estimated from model averaging over 1000 phylogenetic trees. Bold typeface is used when $95 \% \mathrm{Cl}$ does not contain zero, thus can be interpreted as significant effect.

residuals i.e., whether they were normally and homogeneously distributed. The visual inspection of the corresponding diagnostics plots (e.g., Q-Q plot and residuals plotted against fitted values) indicated no obvious deviations from these assumptions. Second, we examined issues about multicollinearity that might potentially lead to instable results and unreliable parameter estimates (Freckleton, 2011; Mundry, 2014). For this purpose, we calculated variance inflation factors (VIF, O'Brien, 2007) to the standard linear model analog of each phylogenetic model that was obtained after excluding the phylogenetic component (as the meaning of VIF is not obvious within the PGLS framework). After the exclusion of incubation period, these analyses showed that collinearity among predictors is not a serious issue to consider further (VIFs < 2). Finally, we verified the absence of influential data points by excluding each of them one by one from the data and then contrasting the derived parameter estimates and fitted values against those that correspond to the model based on the full data. This jackknife procedure revealed no evidence for influential cases strongly affecting the interpretations of the model outcomes.

To characterize the evolutionary history of different sexual traits in different sexes in more detail, we performed ancestral state reconstructions using Mesquite (Maddison and Maddison,

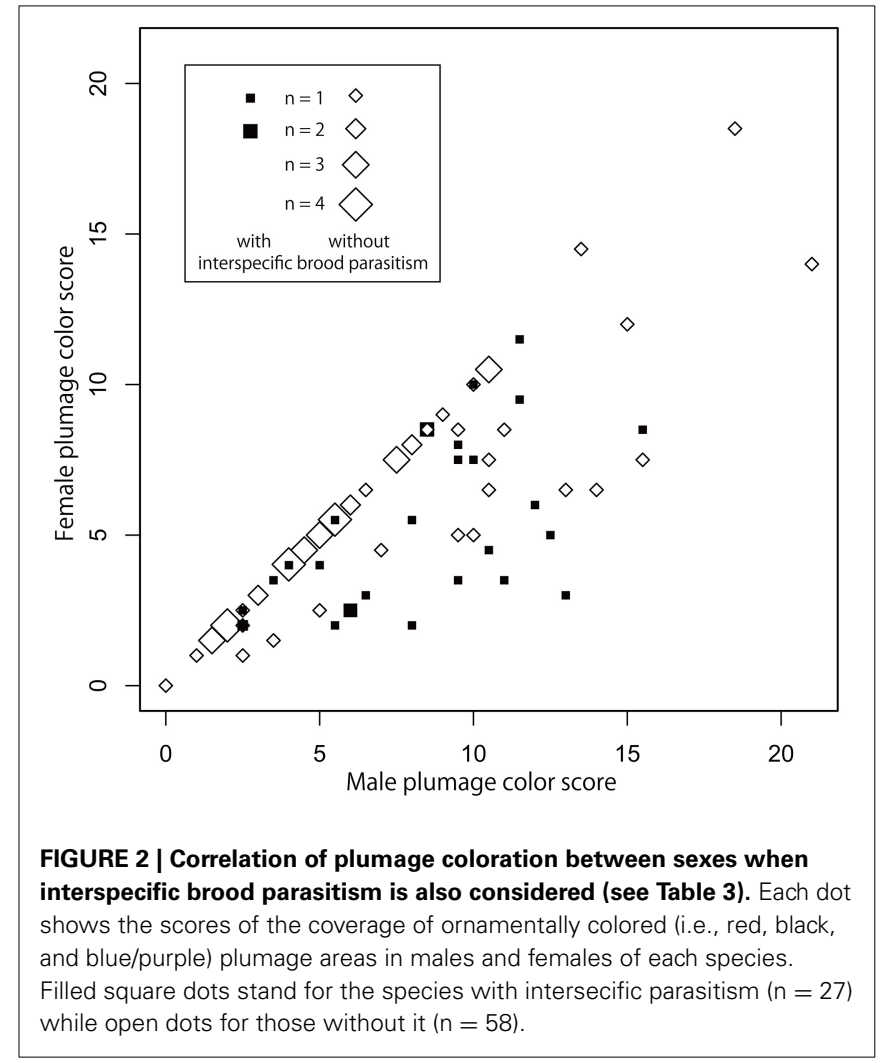

2011) and R package "phytools" (Revell, 2012). To compare the phylogenetic constrains acting on female dance and song, under the prediction that underlying mechanisms that govern trait expressions are shared, we calculated phylogenetic signals $\lambda$ using R package "phytools" (Revell, 2012). In these analyses, we relied on 58 species with a completely bifurcating phylogenetic tree with branch lengths as reported in Arnaiz-Villena et al. (2009). We adopted maximum-likelihood analyses as it has several advantages over the method based on parsimony (Cunningham et al., 1998; Pagel, 1999).

\section{RESULTS}

\section{CORRELATED RESPONSES BETWEEN TRAITS AND SEXES}

Overall, we found that dance complexity of Estrildid finches was not associated interspecifically with the presence of colorful plumage or females song (Tables 1A,B). We also found no correlation between plumage coloration and the other sexual traits (Tables 1C,D). However, we found that females had complex dance in those species in which males also had complex dance (Table 1B), and that females were more colorful in species with colorful males (Table 1D), suggesting correlated responses between sexes (Figure 2). Although we found evidence for research effort confounding estimates of sexual difference in dance complexity, such effects do not confound the focal relationships (Table $\mathbf{1}$ ).

The common ancestor of Estrildid finches is likely to have female dance (Figure 3), but its dance complexity might have been lower for females compared to males (Figure 4). The weak, if any, relationship between female song and dance (Table 1) 


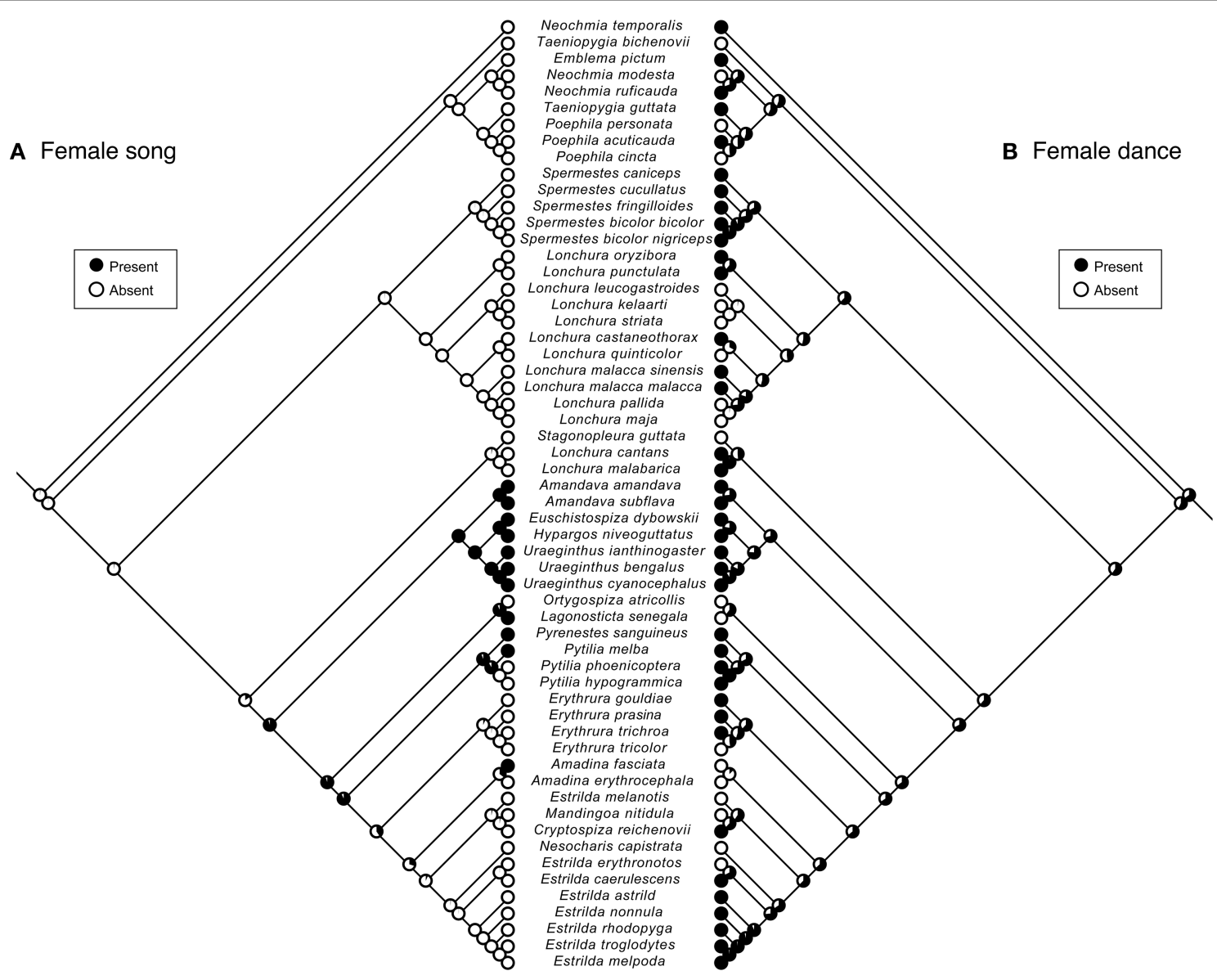

FIGURE 3 | Ancestral reconstruction of behavioral sexual signals in females. Maximum-likelihood reconstruction of ancestral states for the evolution of female song (A) and dance (B) in Estrildid finches, as shown along the phylogeny.

is also apparent when traits are plotted along the branches of the underlying evolutionary tree as binary traits (Figure 3). While phylogenetic signals for presence of female song were strong and statistically significant $(\lambda>0.99, P<0.0001)$, those of female dance was not $(\lambda=0.47, P=0.81)$, indicating that related species tend to be similar with respect to the presence/absence of female song but not dance. This result further indicates that female dance and song followed different evolutionary trajectories. In addition, the common ancestor of Estrildid finches is likely to lack female song but not female dance (Figure 3).

\section{INDEPENDENT EVOLUTION OF FEMALE DANCE AND PLUMAGE COLORATION: THE ROLE OF LIFE-HISTORY TRAITS}

We detected that partially different factors could be responsible for the evolution of dance complexity in males and females (Table 2). While in the PGLS model for males, none of the candidate predictors showed significant associations, in females, dance complexity was positively related to body size when male dance complexity was held constant (Table 2, Figure 5). Furthermore, there was a marginal tendency for intraspecific parasitism to affect dance complexity in both sexes (Table 2).
We also found that different factors might be responsible for the evolution of plumage coloration in males and females (Table 3). While none of the candidate predictors showed strong relationships with male coloration, the parallel analysis for females indicated that this sex had less colorful areas on their plumage under higher risk of brood parasitism (Table 3, Figure 2).

\section{DISCUSSION}

\section{EVOLUTION OF MULTIMODAL SEXUAL SIGNALS}

The evolution of multimodal sexual signals is a topical issue in today's evolutionary biology. This series of phylogenetic comparative analyses in the monogamous Estrildid finches indicated that visual and vocal courtship displays evolved independently (Figure 6), in sharp contrast to the prediction that song and dance constitute a complementary sexual signal. The presence of female song was unrelated to both dance repertoire size and coloration. Although dance complexity was correlated between sexes, the underlying factors that contribute to the exaggeration of dance complexity were only partially shared between males and females. In addition, we also found similar roles for plumage coloration. Plumage coloration was not correlated with the other 


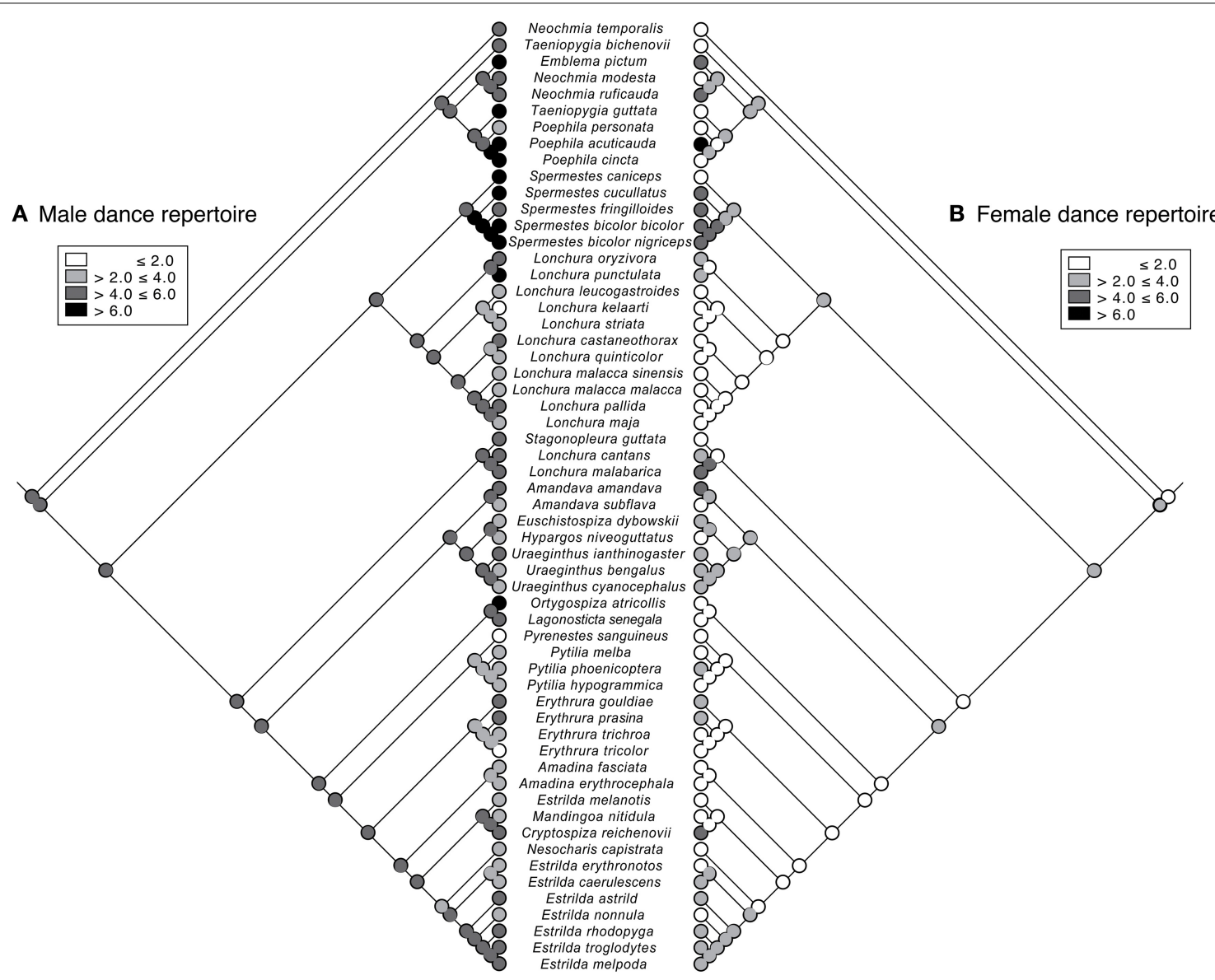

FIGURE 4 | Ancestral reconstruction of dance repertoire. Maximum-likelihood reconstruction of ancestral states for the evolution of dance repertoire size in male (A) and female (B) in Estrildid finches, as shown along the phylogeny.

sexual signals, but was correlated between sexes. These findings suggest that courtship dance and its mutuality between sexes, and plumage coloration in Estrildids evolved under the influence of complicated selection factors, in which both correlated responses between sexes as well as independent selective mechanisms play roles.

Functions of multi-modal displays can be explained in two ways: either multiple displays (e.g., audio-visual displays) are redundant and communicate the same information efficiently, or they convey different messages (Møller and Pomiankowski, 1993; Johnstone, 1996; Candolin, 2003; Bro-Jørgensen, 2010). Our results in association with dance, song, and plumage characters in Estrildid finches support the latter because these three sexual traits were evolutionarily independent of each other. The strong phylogenetic signal for the presence of female song in this groups suggests its evolution is more constrained - perhaps due to the neuroendocrinological and morphological adaptations usually associated with birds song (Bolhuis et al., 2010). Forces of sexual selection that favor ornamental plumage coloration and song do not explain interspecific variation in dance complexity of either sex. This finding indicates that independent selective mechanisms should be considered for explaining the emergence and maintenance of spectacular courtship dance displays in some passerine bird species. Apparently, different mechanisms may be in effect at the within- and between-species level, as it has been reported in males of one Estrildid species (diamond firetail, Stagonopleura guttata) that the quality of courtship dance (i.e., bobbing speed) and plumage ornamentation were positively correlated (Zanollo et al., 2013). Clearly this result is not applicable to the among-species context.

\section{SELECTION FACTORS FOR CORRELATED EVOLUTION BETWEEN SEXES}

One important selection factor that could account for the maintenance of complex display traits is mutual sexual selection to enhance synchronization between pair members. Mirroring behaviors, such as showing similar gestures, or mimicking vocalizations, can be a form of affiliative communication and can contribute to the formation and maintenance of social bonds in a range of animal taxa (e.g., call convergence in budgerigars: Hile et al., 2000; vocal duets in pairs of gibbons; Geissmann and Orgeldinger, 2000; contagious yawning in dogs: Romero et al., 2013), that can be particularly important in many bird species with song duets (Langmore, 1998; Amundsen, 2000; Hall, 2004). Although we did not quantitatively assess the degree of coordination/synchronization of dance displays between sexes, in Estrildid finches, the repertoire of female visual displays is 
Table 2 | Effects of life-history traits on dance complexity in male (A) and female (B) Estrildid finches.

\begin{tabular}{|c|c|c|c|}
\hline Explanatory variable & Coefficient & SE & $95 \% \mathrm{Cl}$ \\
\hline \multicolumn{4}{|l|}{ (A) MALE DANCE REPERTOIRE } \\
\hline Intercept & 4.143 & 1.806 & [0.602 to 7.683$]$ \\
\hline Body size & 0.035 & 0.115 & {$[-0.190$ to 0.260$]$} \\
\hline Clutch size & -0.083 & 0.242 & {$[-0.558$ to 0.392$]$} \\
\hline Coloniality & 0.090 & 0.222 & {$[-0.344$ to 0.525$]$} \\
\hline Interspecific brood parasitism & 0.518 & 0.404 & {$[-0.274$ to 1.311$]$} \\
\hline Intraspecific brood parasitism & 1.248 & 0.679 & {$[-0.083$ to 2.579$]$} \\
\hline Log research effort & 0.257 & 0.332 & {$[-0.393$ to 0.908$]$} \\
\hline \multicolumn{4}{|c|}{ (B) FEMALE DANCE REPERTOIRE } \\
\hline Intercept & -5.910 & 2.448 & {$[-10.708$ to -1.111$]$} \\
\hline Male dance repertoire & 0.480 & 0.146 & [0.194 to 0.766 ] \\
\hline Body size & 0.441 & 0.156 & [0.136 to 0.746$]$ \\
\hline Clutch size & 0.015 & 0.310 & {$[-0.593$ to 0.622$]$} \\
\hline Coloniality & 0.062 & 0.281 & {$[-0.490$ to 0.613$]$} \\
\hline Interspecific brood parasitism & 0.665 & 0.559 & {$[-0.431$ to 1.760$]$} \\
\hline Intraspecific brood parasitism & 1.737 & 0.902 & {$[-0.031$ to 3.504$]$} \\
\hline Log research effort & 0.187 & 0.414 & {$[-0.624$ to 0.998$]$} \\
\hline
\end{tabular}

Each coefficient was estimated from model averaging over 1000 phylogenetic trees. Bold typeface is used when $95 \% \mathrm{Cl}$ does not contain zero, thus can be interpreted as significant effect.

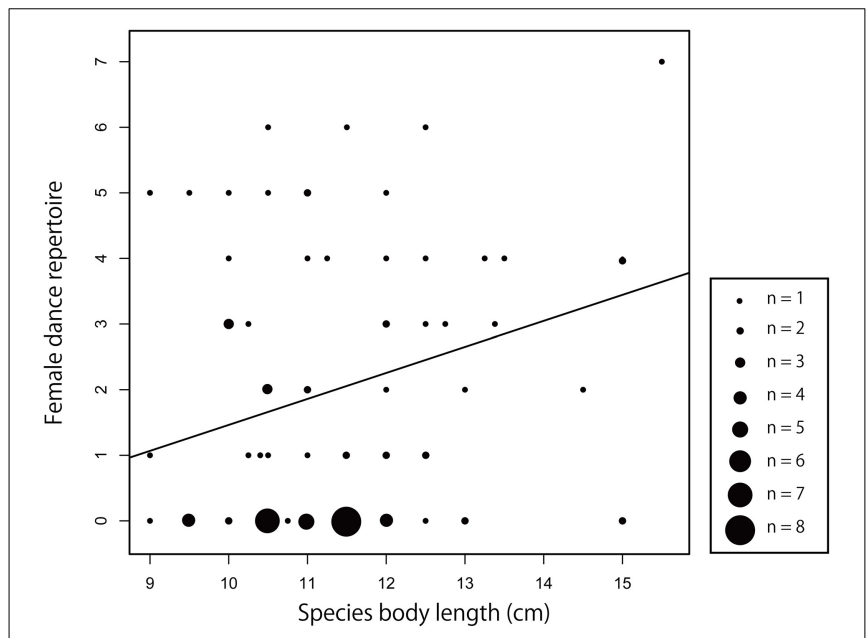

FIGURE 5 | Interspecific association between body size and dance complexity of females. Dots are species-specific estimates, line is the PGLS regression line that is estimated in the corresponding phylogenetic model (Table 2).

covered by that of males without exception. At least some species have been shown to exhibit behavioral synchronization that contributes to better breeding success of pairs (Adkins-Regan and Tomaszycki, 2007; Elie et al., 2010; Mariette and Griffith, 2012; see also Movie S1), and male and female dance repertoire depict correlated evolutionary responses. Therefore, one can reasonably infer that interspecific variation in dance complexity is likely resulted from selection pressures for behavioral coordination between the sexes. However, further studies are needed
Table 3 | Effects of life-history traits on plumage coloration in male (A) and female (B) Estrildid finches.

\begin{tabular}{|c|c|c|c|}
\hline Explanatory variable & Coefficient & SE & $95 \% \mathrm{Cl}$ \\
\hline \multicolumn{4}{|c|}{ (A) MALE PLUMAGE COLORATION } \\
\hline Intercept & 8.035 & 5.648 & [-3.034 to 19.104$]$ \\
\hline Body size & 0.009 & 0.359 & {$[-0.694$ to 0.712$]$} \\
\hline Clutch size & 0.185 & 0.768 & [-1.321 to 0.392$]$ \\
\hline Coloniality & -0.715 & 0.690 & [-2.066 to 0.637$]$ \\
\hline Interspecific brood parasitism & -0.329 & 1.273 & [-2.824 to 2.166$]$ \\
\hline Intraspecific brood parasitism & -1.259 & 2.091 & [-5.358 to 2.839$]$ \\
\hline Log research effort & 0.357 & 1.022 & [-1.645 to 2.360$]$ \\
\hline \multicolumn{4}{|c|}{ (B) FEMALE PLUMAGE COLORATION } \\
\hline Intercept & 1.097 & 2.837 & [-4.463 to 6.658$]$ \\
\hline Male plumage coloration & 0.665 & 0.056 & [0.555 to 0.775$]$ \\
\hline Body size & 0.067 & 0.172 & [ -0.270 to 0.403$]$ \\
\hline Clutch size & -0.190 & 0.390 & [ -0.955 to 0.574$]$ \\
\hline Coloniality & 0.095 & 0.351 & [-0.592 to 0.783$]$ \\
\hline Interspecific brood parasitism & -1.274 & 0.598 & [-2.447 to 0.102$]$ \\
\hline Intraspecific brood parasitism & -0.673 & 1.057 & {$[-2.745$ to 1.399$]$} \\
\hline Log research effort & -0.178 & 0.524 & {$[-1.206$ to 0.850$]$} \\
\hline
\end{tabular}

Each coefficient was estimated from model averaging over 1000 phylogenetic trees. Bold typeface is used when $95 \% \mathrm{Cl}$ does not contain zero, thus can be interpreted as significant effect.

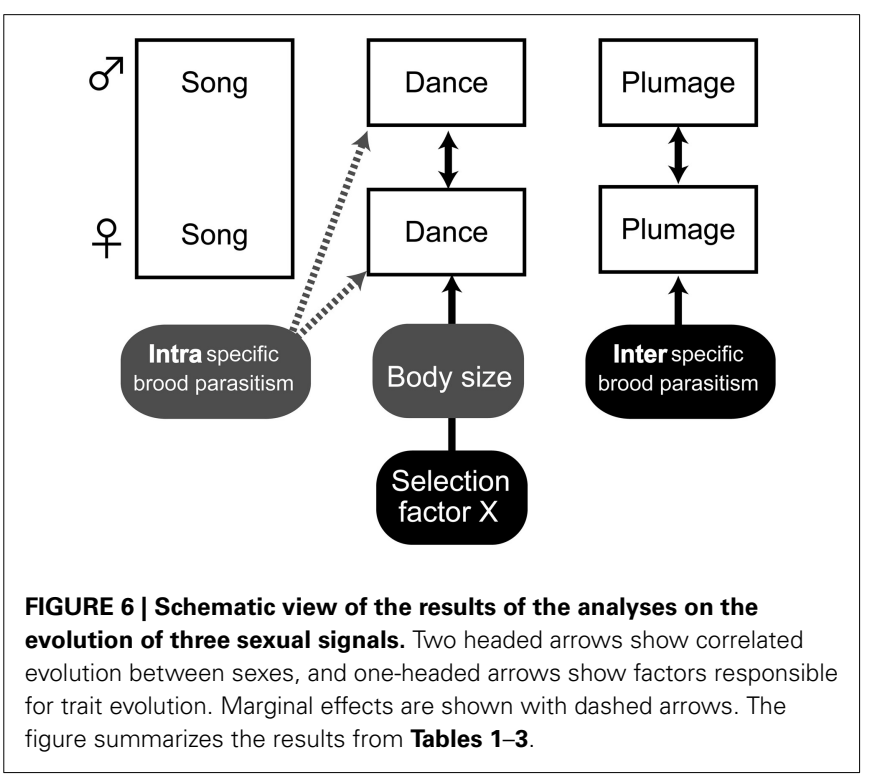

about the importance of such coordinated dance displays between sexes.

We also found that male dance repertoire is consistently larger than that of females and that the phylogenetic signal for the presence of female dance compared with female song is weaker. These findings suggest that species can gain or lose female dance traits under less phylogenetic constrains. Females of some species may have lost the ability to dance similarly to males, and under relaxed selection pressures behavioral sexual dimorphism (in terms of smaller dance complexity in females than in males) may arise 
owing to reduced dance complexity in females. The emergence of sexual dimorphism in dance repertoires may suggest that in addition to correlated evolutionary responses between sexes, female dance complexity may follow partially independent evolutionary routes from that of male dance complexity. Such scenario would be analogous to the findings of comparative studies on female song showing that songbirds might have common ancestors with female song, which was lost in some lineages (Garamszegi et al., 2007; Odom et al., 2014). Which selection factors caused some Estrildid species to lose ancestral dance ability while others have maintained it during their long evolutionary history? Such a question was investigated in a phylogenetic comparative study of New World blackbirds, which appeared to have ancestors with female songs and socially monogamous breeding systems, but in some lineages female song was lost owing to changes in lifehistory such as the emergence of polygyny (Price, 2009). However, Estrildid finches lack drastic variations in mating systems as all species are socially monogamous, which makes the evolution of courtship dances a different story, and subject to further investigation.

Another selection factor that can explain the evolution of complex sexual signals in both sexes is mutual mate preferences. Female ornamentation can evolve when males are choosy, and both sexes can be equally ornamented when mate choice is bidirectional (Amundsen, 2000). This explanation fits to the evolution of plumage coloration in Estrildid finches as females have more ornamental colors in species having colorful males (Figure 2). Moreover, it is also possible that female song and dance evolved similarly in response to male mate choice. However, it is clear that mutual mate choice is not a major common factor, given the observed independent evolution of multiple sexual signals.

\section{LIFE HISTORY TRAIT AND SEXUAL SIGNALS}

Some life-history traits of Estrildid finches that we considered in this study could be candidate factors responsible for the evolution of duet singing and/or dancing, but our result showed that, except body size, none of them can explain interspecific variation in dance complexity (Table 2 ). The only significant pattern we detected indicates that some proportion of the interspecific variation in dance complexity in females can be accompanied by a parallel variation in body size (Table $2 \mathbf{B}$ ). Since body size is associated with numerous life-history traits (Bennett and Owens, 2002), based on our correlative results, it remains difficult to elucidate which correlates of body size is associated with the evolution of courtship dance. A marginally significant tendency for intraspecific parasitism also emerged indicating that dance complexity in both sexes might be related to the degree of cuckoldry within-species. If such relationships were proven to be true, it would suggest that mutual dance evolved in response to increased reproductive cost, a mechanism that would be similar to what has been proposed for duet singing (Hall, 2004). Accordingly, well-coordinated behaviors assured by mutual signaling could lead to better reproductive success when both pair members need to invest more into reproduction when facing with a higher risk of intraspecific brood parasitism. Alternatively, wellcoordinated mutual dance displays could signal pair-bonding to others, which would in turn reduce the risk of becoming the target of intraspecific brood parasitism.

Another interesting finding on the evolution of sexual signals in Estrildid finches was that the coverage of ornamental plumage coloration in females decreased when interspecific brood parasitism was present (Table 3B). This suggests that having more cryptic appearance should be advantageous in terms of having lower chances to be detected by brood parasitic birds that search host nests. Analogous results were reported for species that are parasitized by the brown-headed cowbird Molothrus ater, indicating that males of host species tended to have less conspicuous sexual signals, i.e., songs under higher parasite pressure (Garamszegi and Avilés, 2005). Given that Estrildid females generally stay longer in the nest during nest-building period as compared to males (Payne, 2010), such selection pressures particularly acting on females might serve as a likely explanation for the results we obtained in this study.

Overall, this study highlights the similarity between mutual dance display in Estrildid finches and duet song performance in other songbirds (Hall, 2004), which would contribute to our understanding of functional significance of female dance in Estrildid finches. Moreover, our approach has revealed that studying sex-specific characters in males and females instead of sexual dichromatisms leads to better understanding of the dynamic evolution of sexual traits. However, it remains unclear why some female Estrildid finches sing as surprisingly little is known about vocal communication in this taxonomic group. In contrast with a few limited Estrildid species without females song (e.g., Zebra and Bengalese finches) that have been well studied, singing behaviors of males and females of the rest of the species are largely uncertain (but see Gahr and Güttinger, 1986; Geberzahn and Gahr, 2011, 2013; Kagawa and Soma, 2013; Ota and Soma, 2014), and can be a crucial key to understand the evolution of multimodal communication in future studies.

\section{ACKNOWLEDGMENTS}

During this study, Masayo Soma received a JSPS Grant-in-Aid for Young Scientists (23680027), while László Z. Garamszegi was supported by funds from the Spanish government within the frame of the "Plan Nacional" program (ref. no. CGL2012-38262, CGL2012-40026-C02-01). We are also deeply grateful to the two referees and the editors for helpful comments on the manuscript.

\section{SUPPLEMENTARY MATERIAL}

The Supplementary Material for this article can be found online at: http://www.frontiersin.org/journal/10.3389/fevo.2015. 00004/abstract

Movie S1 | Mutual courtship display of the Java sparrow.

Movie S2 | Male courtship display of the red-cheeked cordon-bleu.

\section{REFERENCES}

Adkins-Regan, E., and Tomaszycki, M. (2007). Monogamy on the fast track. Biol. Lett. 3, 617-619. doi: 10.1098/rsbl.2007.0388

Amundsen, T. (2000). Why are female birds ornamented? Trends Ecol. Evol. 15, 149-155. doi: 10.1016/S0169-5347(99)01800-5

Andersson, M. (1994). Sexual Selection. Princeton, NJ: Princeton University Press. 
Andersson, S., and Prager, M. (2006). "Quantifying colors," in Bird coloration. Vol. 1: Mechanisms and Measurements, eds. G. E. Hill and K. J. McGraw (Cambridge: Harvard University Press), 41-89.

Arnaiz-Villena, A., Ruiz-del-Valle, V., Gomez-Prieto, P., Reguera, R., Parga-Lozano, C., and Serrano-Vela, I. (2009). Estrildinae finches (Aves, Passeriformes) from Africa, South Asia and Australia: a molecular phylogeographic study. Open Ornithol. J. 2, 29-36. doi: 10.2174/1874453200902010029

Badyaev, A. V., and Hill, G. E. (2000). Evolution of sexual dichromatism: contribution of carotenoid- versus melanin-based coloration. Biol. J. Linn. Soc. 69, 153-172. doi: 10.1111/j.1095-8312.2000.tb01196.x

Badyaev, A. V., Hill, G. E., and Weckwort, B. V. (2002). Species divergence in sexually selected traits: increase in song elaboration is related to decrease in plumage ornamentation in finches. Evolution 56, 412-419. doi: 10.1111/j.00143820.2002.tb01350.x

Balmford, A. (1991). Mate choice on leks. Trends Ecol. Evol. 6, 87-92. doi: 10.1016/0169-5347(91)90181-V

Baptista, L. F., Lawson, R., Visser, E., and Bell, D. A. (1999). Relationships of some mannikins and waxbills in the estrildidae. J. Ornithol. 140, 179-192. doi: 10.1007/BF01653597

Bennett, P. M., and Owens, I. P. F. (2002). Evolutionary Ecology of Birds. Oxford: Oxford University Press.

Bolhuis, J. J., Okanoya, K., and Scharff, C. (2010). Twitter evolution: converging mechanisms in birdsong and human speech. Nat. Rev. Neurosci. 11, 747-759. doi: 10.1038/nrn2931

Bostwick, K. S., and Prum, R. O. (2005). Courting bird sings with stridulating wing feathers. Nature 309, 736. doi: 10.1126/science.1111701

Bro-Jørgensen, J. (2010). Dynamics of multiple signalling systems: animal communication in a world in flux. Trends Ecol. Evol. 25, 292-300. doi: 10.1016/j.tree.2009.11.003

Byers, J., Hebets, E., and Podos, J. (2010). Female mate choice based upon male motor performance. Anim. Behav. 79, 771-778. doi: 10.1016/j.anbehav.2010.01.009

Candolin, U. (2003). The use of multiple cues in mate choice. Biol. Rev. 78, 575-595. doi: 10.1017/S1464793103006158

Catchpole, C. K., and Slater, P. J. B. (2008). Bird Song: Biological Themes and Variations, 2nd Edn. Cambridge: Cambridge University Press.

Coleman, S. W., Patricelli, G. L., and Borgia, G. (2004). Variable female preferences drive complex male displays. Nature 428, 742-745. doi: 10.1038/nature02419

Cooper, B. G., and Goller, F. (2004). Multimodal signals: enhancement and constraint of song motor patterns by visual display. Science 303, 544-546. doi: 10.1126/science.1091099

Cunningham, C. W., Omland, K. E., and Oakley, T. H. (1998). Reconstructing ancestral character states: a critical reappraisal. Trends Ecol. Evol. 13, 361-366. doi: 10.1016/S0169-5347(98)01382-2

Dakin, R., and Montgomerie, R. (2009). Peacocks orient their courtship displays towards the sun. Behav. Ecol. Sociobiol. 63, 825-834. doi: 10.1007/s00265-0090717-6

Dalziell, A. H., Peters, R. A., Cockburn, A., Dorland, A. D., Maisey, A. C., and Magrath, R. D. (2013). Dance choreography is coordinated with song repertoire in a complex avian display. Curr. Biol. 23, 1132-1135. doi: 10.1016/j.cub.2013.05.018

Dunn, P. O., Whittingham, L. A., and Pitcher, T. E. (2001). Mating systems, sperm competition, and the evolution of sexual dimorphism in birds. Evolution 55 161-175. doi: 10.1111/j.0014-3820.2001.tb01281.x

DuVal, E. H. (2007). Cooperative display and lekking behavior of the lance-tailed manakin (Chiroxiphia Lanceolata). Auk 124, 1168-1185. doi: 10.1642/00048038(2007)124[1168:CDALBO]2.0.CO;2

Elie, J. E., Mariette, M. M., Soula, H. A., Griffith, S. C., Mathevon, N., and Vignal, C. (2010). Vocal communication at the nest between mates in wild zebra finches: a private vocal duet? Anim. Behav. 80, 597-605. doi: 10.1016/j.anbehav.2010.06.003

Freckleton, R. P. (2011). Dealing with collinearity in behavioural and ecological data: model averaging and the problems of measurement error. Behav. Ecol. Sociobiol. 65, 91-101. doi: 10.1007/s00265-010-1045-6

Friedman, N. R., Hofmann, C. M., Kondo, B., and Omland, K. E. (2009). Correlated evolution of migration and sexual dichromatism in the New World orioles (Ictelus). Evolution 63, 3269-3274. doi: 10.1111/j.1558-5646.2009.00792.x

Fusani, L., Day, L. B., Canoine, V., Reinemann, D., Hernandez, E., and Schlinger, B. A. (2007). Androgen and the elaborate courtship behavior of a tropical lekking bird. Horm. Behav. 51, 62-68. doi: 10.1016/j.yhbeh.2006. 08.005

Gahr, M., and Güttinger, H. R. (1986). Functional aspects of singing in male and female Uraeginthus bengalus (Estrildidae). Ethology 72, 123-131. doi: 10.1111/j.1439-0310.1986.tb00612.x

Galván, I. (2008). The importance of white on black: unmelanized plumage proportion predicts display complexity in birds. Behav. Ecol. Sociobiol. 63, 303-311. doi: 10.1007/s00265-008-0662-9

Garamszegi, L. Z. (2014). Female peak testosterone levels in birds tell an evolutionary story. Behav. Ecol. 25, 700-701. doi: 10.1093/beheco/aru048

Garamszegi, L. Z., and Avilés, J. M. (2005). Brood parasitism by brown-headed cowbirds and the expression of sexual characters in their hosts. Oecologia 143, 167-177. doi: 10.1007/s00442-0041784-z

Garamszegi, L. Z., and Møller, A. P. (2004). Extrapair paternity and the evolution of bird song. Behav. Ecol. 15, 508-519. doi: 10.1093/beheco/arh041

Garamszegi, L. Z., and Møller, A. P. (2012). Untested assumptions about withinspecies sample size and missing data in interspecific studies. Behav. Ecol. Sociobiol. 66, 1363-1373. doi: 10.1007/s00265-012-1370-z

Garamszegi, L. Z., and Mundry, R. (2014). "Multimodel-inference in comparative analyses," in Modern Phylogenetic Comparative Methods and Their Application in Evolutionary Biology: Concepts and Practice, ed L. Z. Garamszegi (New York, NY: Springer), 305-331.

Garamszegi, L. Z., Pavlova, D. Z., Eens, M., and Møller, A. P. (2007). The evolution of song in female birds in Europe. Behav. Ecol. 18, 86-96. doi: 10.1093/beheco/ $\operatorname{arl} 047$

Geberzahn, N., and Gahr, M. (2011). Undirected (solitary) birdsong in female and male blue-capped cordon-bleus (Uraeginthus cyanocephalus) and its endocrine correlates. PLOS ONE 6:e26485. doi: 10.1371/journal.pone. 0026485

Geberzahn, N., and Gahr, M. (2013). Song learning in male and female Uraeginthus cyanocephalus, a tropical songbird species. J. Comp. Psychol. 127, 352-364. doi: 10.1037/a0033154

Geissmann, T., and Orgeldinger, M. (2000). The relationship between duet songs and pair bonds in siamangs, Hylobates syndactylus. Anim. Behav. 60, 805-809. doi: 10.1006/anbe.2000.1540

Goodwin, D. (1982). Estrildid finches of the World. Ithaca, NY: Cornell University Press.

Goymann, W., and Wingfield, J. C. (2014). Male-to-female testosterone ratios, dimorphism, and life history-what does it really tell us? Behav. Ecol. 25, 685-699. doi: 10.1093/beheco/aru019

Hall, M. L. (2004). A review of hypotheses for the functions of avian duetting. Behav. Ecol. Sociobiol. 55, 415-430. doi: 10.1007/s00265-0030741-x

Hall, M. L. (2009). A review of vocal duetting in birds. Adv. Stud. Behav. 40, 67-121. doi: 10.,1016/S0065-3454(09)40003-2

Hile, A. G., Plummer, T. K., and Striedter, G. F. (2000). Male vocal imitation produces call convergence during pair bonding in budgerigars, Melopsittacus undulatus. Anim. Behav. 59, 1209-1218. doi: 10.1006/anbe.1999.1438

Hill, G. E. (1991). Plumage coloration is a sexually selected indicator of male quality. Nature 350, 337-339. doi: 10.1038/350337a0

Hill, G. E. (2006). "Female mate choice for ornamental coloration," in Bird Coloration, Vol. 2: Function and Evolution, eds G. E. Hill and K. J. McGraw (Cambridge: Harvard University Press), 137-200.

Jawor, J. M., and Breitwisch, R. (2003). Melanin ornaments, honesty, and sexual selection. Auk 120, 249-265. doi: 10.1642/00048038(2003) 120 [0249:MOHASS]2.0.CO;2

Jetz, W., Thomas, G. H., Joy, J. B., Hartmann, K., and Mooers, A. O. (2012). The global diversity of birds in space and time. Nature 491, 444-448. doi: 10.1038 /nature11631

Johnson, K. P. (2000). The evolution of courtship display repertoire size in the dabbling ducks (Anatini). J. Evol. Biol. 13, 634-644. doi: 10.1046/j.14209101.2000.00200.x

Johnstone, R. A. (1996). Multiple displays in animal communication: 'backup signals' and 'multiple messages'. Philos. Trans. R. Soc. Lond. B. Biol. Sci. 351, 329-338. doi: 10.1098/rstb.1996.0026

Kagawa, H., and Soma, M. (2013). Song performance and elaboration as potential indicators of male quality in Java sparrows. Behav. Process. 99, 138-144. doi: 10.1016/j.beproc.2013.07.012 
Ketterson, E. D., Nolan, V., and Sandell, M. (2005). Testosterone in females: mediator of adaptive traits, constraint on sexual dimorphism, or both? Am. Nat. 166 S85-S98. doi: 10.1086/444602

Keyser, A. J., and Hill, G. E. (1999). Condition-dependent variation in the blueultraviolet coloration of a structurally based plumage ornament. Proc. Biol. Sci. 266, 771-777. doi: 10.1098/rspb.1999.0704

Langmore, N. E. (1998). Functions of duet and solo songs of female birds. Trends Ecol. Evol. 13, 136-140. doi: 10.1016/S0169-5347(97)01241-X

Lefebvre, L., Reader, S. M., and Sol, D. (2004). Brains, innovations and evolution in birds and primates. Brain Behav. Evol. 63, 233-246. doi: 10.1159/0000 76784

Logue, D. M., and Hall, M. L. (2014). Migration and the evolution of duetting in songbirds. Proc. Biol. Sci. 281, 20140103. doi: 10.1098/rspb.2014.0103

Madden, J. (2001). Sex, bowers and brains. Proc. Biol. Sci. 268, 833-838. doi: 10.1098/rspb.2000.1425

Maddison, W. P., and Maddison, D. R. (2011). Mesquite: a modular system for evolutionary analysis. Available online at: http://mesquiteproject.org

Malacarne, G., Cucco, M., and Camanni, S. (1991). Coordinated visual displays and vocal duetting in different ecological situations among Western Palearctic non-passerine birds. Ethol. Ecol. Evol. 3, 207-219. doi: 10.1080/08927014.1991.9525369

Mariette, M. M., and Griffith, S. C. (2012). Nest visit synchrony is high and correlates with reproductive success in the wild Zebra finch Taeniopygia guttata. J. Avian Biol. 43, 131-140. doi: 10.1111/j.1600-048X.2012.05555.x

Masatomi, H. (1983). Some observations on mating behaviour of several cranes in captivity. J. Ethol. 1, 62-69. doi: 10.1007/BF02347831

Mazerolle, M. J. (2013). AICcmodavg: model selection and multimodel inference based on (Q) AIC (c). Available online at: http://cran.r-project.org/web/ packages/AICcmodavg/AICcmodavg.pdf

Møller, A. P., Garamszegi, L. Z., Gil, D., Hurtrez-Boussès, S., and Eens, M. (2005) Correlated evolution of male and female testosterone profiles in birds and its consequences. Behav. Ecol. Sociobiol. 58, 534-544. doi: 10.1007/s00265-0050962-2

Møller, A. P., and Pomiankowski, A. (1993). Why have birds got multiple sexual ornaments? Behav. Ecol. Sociobiol. 32, 167-176. doi: 10.1007/BF001 73774

Mountjoy, D. J., and Leger, D. W. (2001). Vireo song repertoires and migratory distance: three sexual selection hypotheses fail to explain the correlation. Behav. Ecol. 12, 98-102. doi: 10.1093/oxfordjournals.beheco.a000385

Mundry, R. (2014). "Statistical issues and assumptions of phylogenetic generalised least squares," in Modern Phylogenetic Comparative Methods and Their Application in Evolutionary Biology: Concepts and Practice, ed L. Z. Garamszegi (New York, NY: Springer), 131-153.

Nuechterlein, G. L., and Storer, R. W. (1982). The pair-formation displays of the western grebe. Condor 84, 350-369.

Nunn, C. L., Altizer, S., Jones, K. E., and Sechrest, W. (2003). Comparative tests of parasite species richness in primates. Am. Nat. 162, 597-614. doi $10.1086 / 378721$

O'Brien, R. M. (2007). A caution regarding rules of thumb for variance inflation factors. Qual. Quant. 41, 673-690. doi: 10.1007/s11135-006-9018-6

Odom, K. J., Hall, M. L., Riebel, K., Omland, K. E., and Langmore, N. E. (2014) Female song is widespread and ancestral in songbirds. Nat. Commun. 5, 3379 doi: $10.1038 /$ ncomms4379

Orme, D. (2012). The caper package: comparative analysis of phylogenetics and evolution in R. Available online at: http://cran.r-project.org/web/packages/ caper/vignettes/caper.pdf

Ota, N., and Soma, M. (2014). Age-dependent song changes in a closed-ended vocal learner: elevation of song performance after song crystallization. J. Avian Biol. (in press) doi: 10.1111/jav.00383

Owens, I. P. F., and Hartley, I. R. (1998). Sexual dimorphism in birds: why are there so many different forms of dimorphism? Proc. R. Soc. B Biol. Sci. 265, 397-407. doi: 10.1098/rspb.1998.0308

Pagel, M. (1999). Inferring the historical patterns of biological evolution. Nature 401, 877-884. doi: 10.1038/44766

Patricelli, G. L., Walsh, G., and Borgia, G. (2002). Male displays adjusted to female's response. Nature 415, 279-280. doi: 10.1038/415279a

Payne, R. B. (2010). "Family Estrildidae (waxbills)," in Handbook of the Birds of the World, 15, eds J. del Hoyo, A. Elliott, and D. A. Christie (Barcelona: Lynx Edicions), 234-377.
Price, J. J. (2009). Evolution and life-history correlates of female song in the New World blackbirds. Behav. Ecol. 20, 967-977. doi: 10.1093/beheco/arp085

Price, J. J., Lanyon, S. M., and Omland, K. (2009). Losses of female song with changes from tropical to temperate breeding in the New World blackbirds. Proc. Biol. Sci. 276, 1971-1980. doi: 10.1098/rspb.2008.1626

Pruett-Jones, S. G., and Pruett-Jones, M. A. (1990). Sexual selection through female choice in Lawes' Parotia, a lek-mating bird of paradise. Evolution 44, 486-501.

Prum, R. O. (1990). Phylogenetic analysis of the evolution of display behavior in the Neotropical manakins (Aves: Pipridae). Ethology 84, 202-231. doi: 10.1111/j.1439-0310.1990.tb00798.x

Prum, R. O. (1998). Sexual selection and the evolution of mechanical sound production in manakins (Aves: Pipridae). Anim. Behav. 55, 977-994. doi: 10.1006/anbe.1997.0647

R Core Team (2013). R: A Language and Environment for Statistical Computing. Vienna, Austria: R Foundation for Statistical Computing. Available online at: http://www.R-project.org/

Read, A. F., and Weary, D. M. (1992). The evolution of bird song: comparative analyses. Philos. Trans. R. Soc. Lond. B. Biol. Sci. 338, 165-187. doi: $10.1098 /$ rstb. 1992.0137

Restall, R. (1996). Munias and Mannikins. Sussex: Pica Press.

Revell, L. J. (2012). Phytools: an R package for phylogenetic comparative biology (and other things). Methods Ecol. Evol. 3, 217-223. doi: 10.1111/j.2041210X.2011.00169.x

Romero, T., Konno, A., and Hasegawa, T. (2013). Familiarity bias and physiological responses in contagious yawning by dogs support link to empathy. PLoS ONE 8:e71365. doi: 10.1371/journal.pone.0071365

Scholes, E. (2008). Evolution of the courtship phenotype in the bird of paradise genus Parotia (Aves: Paradisaeidae): homology, phylogeny, and modularity. Biol. J. Linn. Soc. 94, 491-504. doi: 10.1111/j.1095-8312.2008.01012.x

Searcy, W. A. (1992). Song repertoire and mate choice in birds. Am. Zool. 32, 71-80. doi: $10.1093 / \mathrm{icb} / 32.1 .71$

Searcy, W. A., and Andersson, M. (1986). Sexual selection and the evolution of song. Ann. Rev. Ecol. Syst. 17, 507-533.

Shutler, D. (2011). Sexual selection: when to expect trade-offs. Biol. Lett. 7, 101-104. doi: 10.1098/rsbl.2010.0531

Sorenson, M., Balakrishnan, C. N., and Payne, R. B. (2004). Clade-limited colonization in brood parasitic finches (Vidua spp.). Syst. Biol. 53, 140-153. doi: $10.1080 / 10635150490265021$

Torres, R., and Velando, A. (2003). A dynamic trait affects continuous pair assessment in the blue-footed booby, Sula nebouxii. Behav. Ecol. Sociobiol. 55, 65-72. doi: 10.1007/s00265-003-0669-1

Wachtmeister, C. A. (2001). Display in monogamous pairs: a review of empirical data and evolutionary explanations. Anim. Behav. 61, 861-868. doi: $10.1006 /$ anbe.2001.1684

Yom-Tov, Y. (2001). An updated list and some comments on the occurrence of intraspecific nest parasitism in birds. IBIS 143, 133-143. doi: 10.1111/j.1474919X.2001.tb04177

Zanollo, V., Griggio, M., Robertson, J., and Kleindorfer, S. (2013). Males with a faster courtship display have more white spots and higher pairing success in the Diamond Firetail, Stagonopleura guttata. Ethology 119, 344-352. doi: $10.1111 /$ eth. 12071

Conflict of Interest Statement: The authors declare that the research was conducted in the absence of any commercial or financial relationships that could be construed as a potential conflict of interest.

Received: 22 October 2014; accepted: 08 January 2015; published online: 09 February 2015

Citation: Soma M and Garamszegi LZ (2015) Evolution of courtship display in Estrildid finches: dance in relation to female song and plumage ornamentation. Front. Ecol. Evol. 3:4. doi: 10.3389/fevo.2015.00004

This article was submitted to Behavioral and Evolutionary Ecology, a section of the journal Frontiers in Ecology and Evolution.

Copyright (C) 2015 Soma and Garamszegi. This is an open-access article distributed under the terms of the Creative Commons Attribution License (CC BY). The use, distribution or reproduction in other forums is permitted, provided the original author(s) or licensor are credited and that the original publication in this journal is cited, in accordance with accepted academic practice. No use, distribution or reproduction is permitted which does not comply with these terms. 